\title{
A Study on Water Absorption and Mechanical Properties in Epoxy-Bamboo Laminate Composite with Varying Immersion Temperatures
}

https://doi.org/10.1515/eng-2020-0091

Received Nov 04, 2019; accepted May 28, 2020

\begin{abstract}
Bamboo laminate composites could be the alternative materials in outdoor application. However, the life time prediction of this composite in humid environment became a concern considering hydrophilic property of the bamboo fibre. This research aimed to assess the changes of mechanical properties in the composite with the sorption of water. It employed hand lay-up method in developing the laminate composites with epoxy as the matrix and woven bamboo as the reinforced material. Water sorption characteristic was evaluated through a gravimetric analysis for different water immersion temperatures. The sorption on water was studied by four weeks immersion in room temperature as well as in elevated temperatures of $50^{\circ}$ and $80^{\circ} \mathrm{C}$. Tensile test was performed to evaluate the mechanical properties of the composite. This research clearly showed the significant effect of bamboo fibre on the strength and water sorption behaviour of the composites. It was observed that the rate of water absorption depends on temperature of immersion. Larger debonding between the bamboo fibre and the epoxy matrix was found in higher water immersion temperature. The results of this study emphasized the importance of considering the deterioration of mechanical properties in outdoor applications of bamboo composite highly exposed to high temperature and humidity
\end{abstract}

Keywords: bamboo fibre, laminate composite, water sorption, mechanical properties, degradation

\footnotetext{
^Corresponding Author: Indah Widiastuti: UNS;
} Email: indahwidiastuti@staff.uns.ac.id Yuniar Ratna Pratiwi, Dwi Noor Cahyo: UNS

əopen Access. ( 2020 I. Widiastuti et al., published by De Gruyter. 4.0 License

\section{Introduction}

Currently, natural fibre-reinforced composites have gained more attention due to its relative lower cost and better renewability. Bamboo is a natural reinforcing composite fibre which considered acceptable as structural material considering its high strength and stiffness $[1,2]$. The strength to weight ratio of bamboo is higher than that of plain steel an lumber as its tensile strength is approximately two times higher than lumber's [3]. If it shows excellent properties for structural purposes, using bamboo in wider application, especially for load bearing structures, appears to be promising. The manufacture of bamboo-based thermoplastic composites for applications as valued-added panels, such as window frames, fencing, roofing, decking and sliding, is increasingly popular [4]. While many reports on evaluation of fibre-based bamboopolymer composites are exist in the literature [2, 5-9], there are few publications on characterization of bamboo composites based on bamboo laminate in polymeric matrix $[1,3]$.

Due to its hydrophilic characteristic, the natural fibre reinforced polymer composites are mostly used for interior application [2]. The presence of water in bamboo fibre leads to weak interfacial bonding between fibres and matrix which in turn deteriorate the mechanical properties of resulted composite [10]. Based on experiments on water uptake, several studies on diffusion of water into bamboo-based polymer composites have been reported [2, $5,10,11]$. Various efforts have been performed to enhance interface between the hydrophilic bamboo fibre and the hydrophobic polymer matrix. Kushwaha and Kumar (2) utilized a surface modification treatment by silanization to reduce the water absorption rate in a bamboo reinforced polyester composite. Before silane treatment, the bamboo fibres were mercerized to eliminate the lignin and waxes in their surfaces. Heat treatment of the bamboo fibre also has been shown to improve bonding between the matrix and fibres which in turn enhancing water resistance of the composite [12]. From their experiments on bamboo-HDPE 
composites, it was found that the rate of water sorption decreased with increasing temperature of bamboo fibre heat treatment.

Extensive study on the effect of water sorption in natural fibre reinforced polymer composites is off significant interest, especially when designing a load bearing application with strong exposure to outdoor environment or contact with aqueous media. The study should not only consider the amount of the absorbed water, but also the effect of water temperature and the time of immersion [13]. An attempt has been made in this study to characterize the bamboo fibre to aid the increasing utilization of bamboo-based polymer composites in outdoor applications. It evaluated the water sorption of lamina-based bamboo composite in epoxy matrix under different environment temperatures. It is necessary to study the water sorption characteristics in bamboo polymer composite because poor resistance of the fibres to humidity can have undesirable effects on the mechanical performance of the resulted composites. Further, this article also reports change of physical and mechanical properties of the composites which exposed to wet environment. By evaluating the properties degradation, the water uptake into this material can be minimized in some ways.

\section{Material and methods}

\subsection{Materials}

The materials used in this study are epoxy as the matrix material and bamboo fibre in woven mat form. Sheets of woven bamboo (Figure 1) were obtained from traditional craftsmen in Central Java, Indonesia, made from local bamboo species. The woven bamboo mats consisted of bamboo strips with a thickness of $0.5 \mathrm{~mm}$ and $5-8 \mathrm{~mm}$ of width. The bamboo species used was bambu wulung (Gigantochloa atroviolacea), a local indigenous plant abundantly grows in Indonesia. The woven bamboo sheets were cut in the size of standard test specimens for tensile test following ASTM D3039 $\left(256 \times 25.6 \mathrm{~mm}^{2}\right)$. Before composite processing, the bamboo mats were firstly washed and then immersed in distilled water for 4 hours.

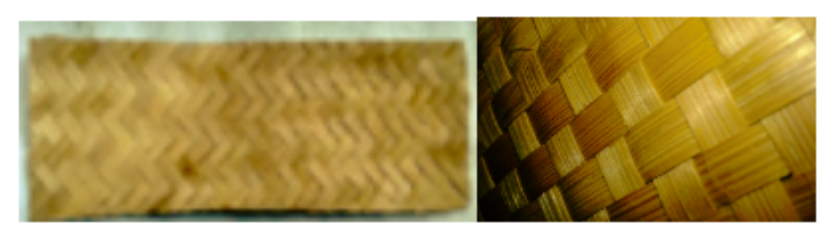

Figure 1: Woven Bamboo Mat Derived from Local Craftsmen
The polymer matrix for laminate composite is Epoxy Resin EPR 174 (eposchon A) which mixed with Epoxy Hardener EPH 555 from The HK Yutai New Technology at a ratio of $1: 1$. They were manually stirred together until feels warm.

\subsection{Physical Treatment}

The fibre treatment was performed physically by drying the woven mat in a laboratory oven for 4 (four) hours at various levels of temperature. Before drying, the mats were immersed in pure water for 4 (four) hours to ensure similar level of water content inside the woven bamboo mat. Previous study on analysing effect of bamboo fibre treatment [14] indicated that $150^{\circ} \mathrm{C}$ drying temperature providing the most excellent mechanical properties. Lower mechanical properties were observed for the composite containing bamboo fibre treated in drying condition above $150^{\circ} \mathrm{C}$ due to structural changes.

\subsection{Specimens Preparation}

The woven bamboo mats and the epoxy were subjected to hand lay-up process using glass mould in alternately two layers of bamboo mats and three layers of epoxy resin. Before pouring the mixture of epoxy, a release agent was sprayed into the internal surfaces of the mould to facilitate easy removal of the composites. The bamboo mats were placed after the first layer of epoxy covered the mould lower surface. Lastly, the epoxy mixture was poured on the top surface of bamboo mat producing about $4 \mathrm{~mm}$ thickness of laminate composite. It was ensured that the composite consisted of $25 \%$ epoxy resin from its total volume. A load of $25 \mathrm{~kg}$ was applied to the moulds. They were then stored for 24 hours at room temperature before removing for further testing.

\subsection{Water Immersion}

The immersion test for bamboo laminate composites used standard test method of ASTM D570. This method provides standard for determining water absorption rate of plastic materials. The rectangular composite specimens in the size of ASTM D3039 standard tensile specimen were completely immersed in pure water in a ration of five specimen to $1500 \mathrm{ml}$ of liquid. The specimens were put in a holder inside a rectangular glass container and immersed to approach point of saturation under three different con- 
ditions: (1) room temperature $\left( \pm 25^{\circ} \mathrm{C}\right)$ and thermal chamber set at (2) $50^{\circ} \mathrm{C}$ and (3) $80^{\circ} \mathrm{C}$. The water uptake during the diffusion process was determined using a gravimetric measurement. Weight of the specimens were periodically measured for 480 hours and the apparent weight gain $\left(M_{t}\right)$ were calculated using the following relationship.

$$
M_{t}(\%)=\frac{m_{t}-m_{0}}{m_{0}} \times 100 \%
$$

where $m_{t}$ and $m_{0}$ are the weight of bamboo composite specimen in gram during and before water immersion, respectively.

\subsection{Mechanical Testing}

Specimens for the tensile test were removed from the mould using a pen-knife in the dimensions of $256 \times 25.6$ $\times 4 \mathrm{~mm}^{3}$. Five samples were tested according to ASTM D3039 procedure using a Universal Testing Machine at a crosshead speed of $2 \mathrm{~mm} / \mathrm{min}$. The tensile tests were conducted at $25 \pm 5^{\circ} \mathrm{C}$ temperature with $50 \%$ humidity.

\subsection{Scanning Electron Microscopy}

The specimen surfaces are directly examined under scanning electron microscope [15] Hitachi SU3500 to identify the morphological characterization. Before taken the photomicrographs, a thin film was vacuum evaporated on the samples to enhance their conductivity. The fractured of composite specimens after tensile test were examined to observe the surface morphology, such as the interfacial interaction between the woven bamboo and epoxy.

\section{Result}

\subsection{Water Sorption Behaviour}

Water absorption curves of pure epoxy and bamboo reinforced epoxy composites are illustrated in Figure 2 where the percentage of weight gain is plotted against time. Figure 2 shows the effect of the incorporation of bamboo fibre on the water absorption of epoxy specimens in room temperature immersion. Considering practical reasons, the water absorption tests were carried out for no longer than 4 (four) weeks so equilibrium was not reached. It is clear from Figure 2 that in the same temperature, more water uptake is shown by the bamboo-epoxy composite compared to the pure epoxy specimen. It is evident that the bamboo-based material is more sensitive to water sorption, with more than 3.5\% weight gain at 480 hours of immersion. When bamboo fibre is incorporated, the water uptake of epoxy material is increased as water diffuses through the porous structure of bamboo fibre. Epoxy material is hydrophobic in which water absorbability can neglected. Therefore, higher hydrophilic nature of cellulosic fibre is the main reason of higher water sorption in bamboo-based composite and the penetration of water is mainly through the cross-sectional portion of the fibre by capillary mechanism [16]. This behaviour is in accordance with previous report $[10,11]$ which considered various weight fractions of bamboo fibre in an epoxy matrix. In natural-fibre based composites, the free $\mathrm{OH}$ groups of cellulose will come in contact with water and form hydrogen bonding which results in increasing of water absorption $[17,18]$.

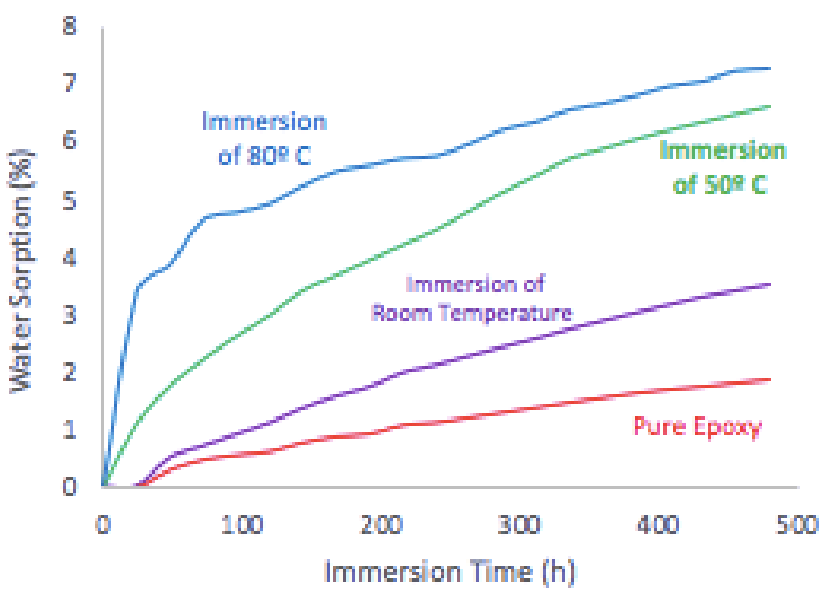

Figure 2: Water Sorption Behaviour of Bamboo-Epoxy Composites in Various Immersion Temperatures

Figure 2 also shows the variation of the water absorption of bamboo-epoxy composites as a function of time for different immersion temperatures. The effect of temperature on the water absorption process is necessary when considering service application. Accordingly, the composite specimens were also immersed in water at $50^{\circ}$ and $80^{\circ} \mathrm{C}$. In all immersion temperatures, the sorption of water increases with immersion time, but a saturation point could not be observed during 480 hours of immersion.

The figure indicates that the rate of water absorption and amount of water sorption increase with increase in environment temperature. It shows significant increase of weight gain at elevated temperature, which found to have $6.6 \%$ and $7.8 \%$ water uptake after 480 hours immersion at $50^{\circ}$ and $80^{\circ} \mathrm{C}$, respectively. Similar trend was observed by Mael, Pierre-Yves (19) on Polyamide as well as by Es- 
lami, Taheri-Behrooz (20) on glass-fibre reinforces plastic (GFRP). Higher temperatures tend to accelerate the water diffusion behaviour. It is believed that the phenomenon is due to quicker movement of water molecules at higher temperature [21, 22]. At high temperature, there is also a chance of breakage of the addition H-bonds created in the cellulosic network [23]. It paves way for water diffusion through these additional parts which in turn increases the absorption of water into the material.

\subsection{Mechanical Properties}

This section presents the changes of performance on the epoxy-bamboo laminate composite during water sorption, which is represented by its tensile properties. The information of the composite's mechanical properties is required to evaluate stability of material during it service life.

This research found that epoxy specimens used as the composite matrix has an average tensile strength of 3.2 MPa and $4 \mathrm{MPa}$ of elastic modulus. Meanwhile, the average values of tensile strength and elastic modulus for each level of immersion temperature of the resulted composites are shown in Table 1 . This clearly shows a significant improvement of pure epoxy after reinforcement. Table 1 also shows that the tensile strength decreases progressively as a function of water immersion temperature, from $45.4 \mathrm{MPa}$ in dry specimen to around $29 \mathrm{MPa}$ in specimen immersed in $80^{\circ} \mathrm{C}$ temperature. Furthermore, the figure also shows that the elastic modulus decreases with immersion temperature, with a decrease of $18 \%$ from $1751.8 \mathrm{MPa}$ in room temperature of immersion. Lower modulus due to increasing water uptake may lead to a higher strain since it causes the polymer molecules to relax more easily.

Table 1: Tensile Properties of The Composites with Varying Immersion Temperatures

\begin{tabular}{lll}
\hline Treatment & $\boldsymbol{\sigma}(\mathrm{MPa})$ & $\mathrm{E}(\mathrm{MPa})$ \\
\hline Dry specimen & $45.4 \pm 2.2$ & $1751.8 \pm 73.7$ \\
RT immersion & $35.2 \pm 3.7$ & $1431.0 \pm 90.1$ \\
$50^{\circ} \mathrm{C}$ immersion & $34.4 \pm 1.5$ & $1264.6 \pm 90.3$ \\
$80^{\circ} \mathrm{C}$ immersion & $29.4 \pm 2.2$ & $1122.2 \pm 41.7$ \\
\hline
\end{tabular}

Since it has been revealed from Figure 2 that the amount of absorbed water is linearly dependent on immersion temperature, it can be concluded that the mechanical properties of the composite is a function of its water uptake. The decreasing of material strength with increasing amount of water sorption is in agreement with previ- ous research on Polylactic acid (PLA) a bio-based material derived from vegetable starches [24]. The phenomenon was also revealed from a study on cotton fabric-reinforced geopolymer composites [25], as the flexural strength decreased markedly after absorption of water. The decrease in mechanical properties with increase in liquid uptake could be caused by the formation of hydrogen bonding between cellulose fibres and water molecules [26]. As a natural fibre, bamboo possess many hydroxyl groups which makes the resulted composites to have lower water resistance.

The presence of water within the natural fibre reinforced polymer allows more macromolecular chains movement in the amorphous phase considering that liquid uptake plays the role of a plasticizer [19, 27]. This plasticisation induces large changes in the mechanical behaviour indicated by higher strain and a decrease in the glass transition temperature (Tg). Decreasing of glass transition temperature is a common consequence observed with the existence of liquid and organic solvent within polymeric material [27]. It has been revealed by Yu, Hearon (28) that the shift of glass transition temperature on a polyurethanebased material affected a transformation from glassy to viscoelastic behaviour which resulting in a mechanical behaviour transformation. In order to have a better understanding on the surface morphology of the composites after water sorption, the result of the scanning electron microscopy [15] is presented in the following section.

\subsection{Surface Morphology}

The fracture surface study of the laminated bamboo-epoxy composite after the tensile test for various immersion temperatures has shown in Figure 3. The cross-sectional observation of the specimens was focused on interfacial of the bamboo fibre and the matrix. Figure 3(a) presents different layers of the epoxy matrix and bamboo laminate. As shown in this figure, the SEM photograph of the fractured surface of the dry material indicates good adhesion between bamboo fibres and the epoxy matrix.

However large spaces were found in the specimens immersed in the water. It is observed from Figures 3(b) and 3(c) for immersion in room temperature and higher temperature, respectively, that a debonding developed between the fibre and matrix in the water immersed specimens. The water molecules penetrate in the bamboo laminate composite and affects the interfacial adhesion between fibre and the matrix. The hydrophilic nature of bamboo fibre causes the laminate composite to absorb more water. As clearly seen in Figure 3(b), the water uptake 

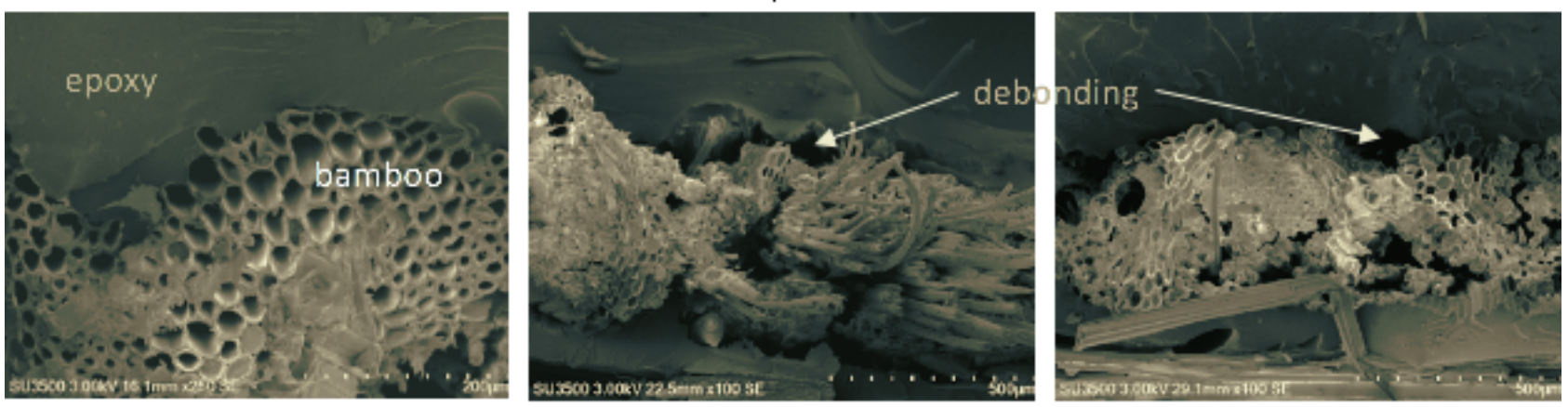

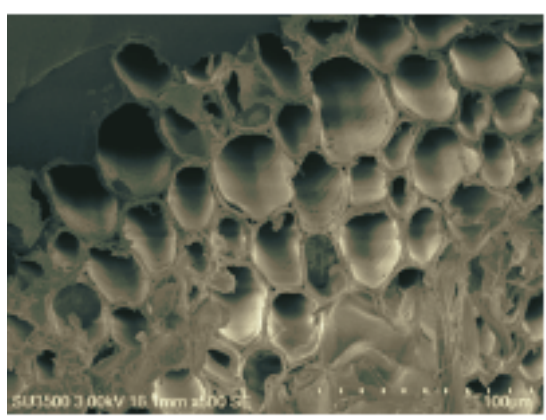

(a) Dry spesimen

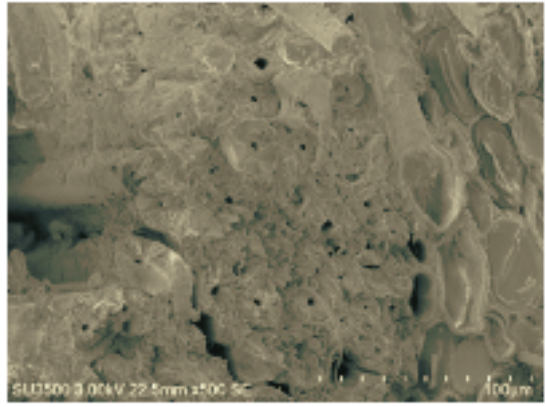

(b) RT immersed specimen

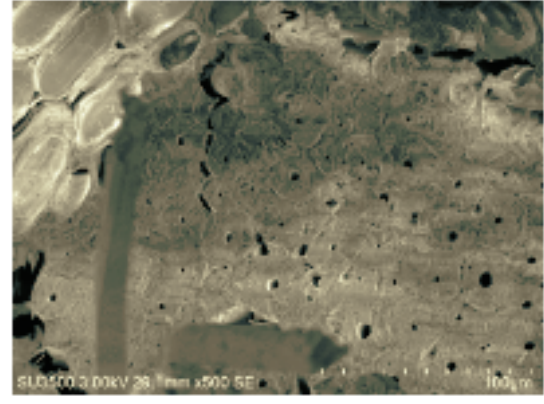

(c) $50^{\circ}$ immersed spesimen

Figure 3: Scanning Electron Microscopy [15] photograph of the fractured specimens

causes swelling of bamboo fibres. The swelling creates micro-cracks in the polymer matrix and eventually lead to debonding between the fibre and the matrix $[25,26]$. This fact provides a clear picture on the reason for the degradation of mechanical properties after water absorption. The sorption-induced swelling stress may also lead to composite failure, delamination and loss of structural integrity, especially due to varying liquid content within the material.

In higher immersion temperature $\left(50^{\circ} \mathrm{C}\right)$, as shown in Figure 3(c), more swelling of bamboo fibre is observed from the SEM image compared to that in room temperature immersion. The SEM evidence in this figure support the weight gain data presented in Figure 2 which shows that the weight gain is higher for sample immersed at elevated temperature than at room temperature. The quicker movement of water molecules at high temperature leads to more capillarity which enhance the water attack along fibre-matrix interface. It supports the findings on hemp fibre polymer composites [26] that a different sorption behaviour is exist for room temperature and high temperature of immersion. There are different aging mechanisms in different immersion temperatures which attributed to different diffusivity of water into the composite material.

\section{Conclusion}

A systematic investigation of water sorption into a bamboobased polymer composite at different immersion temperatures has been reported. The experiment results show the time-dependent water sorption, which is highly influenced by the environment temperature. With the gravimetric analysis, amount of water uptake within the composite increases with temperature of immersion. This article also confirms a significant impact of water absorption on mechanical properties of epoxy-bamboo composite through the measurement of tensile properties. Exposure to water results in significant drop in tensile properties due to swelling of hydrophilic bamboo fibre which induces deterioration of the fibre-matrix interface. At elevated temperatures, the more debonding within the interface occurs and enhances the degradation rate of the mechanical properties. The response of this material to water absorption was consistent with other reports on various types of naturalbased composites. The results show progressive decrease of the modulus and strength by increasing of water content inside the material. Further research work is being undertaken to evaluate the performance of the composites with varying chemical fibre treatmentst as well as analyzing water absorption kinetics using fractal calculus. 
Acknowledgement: The authors acknowledge the Fundamental Research Grant of the Institute of Research and Community Service Universitas Sebelas Maret, Surakarta, Indonesia for supporting the research work.

\section{References}

[1] Verma CS, Chariar VM. Stiffness and strength analysis of four layered laminate bamboo composite at macroscopic scale. Compos, Part B Eng. 2013;45(1):369-76.

[2] Kushwaha PK, Kumar R. Studies on Water Absorption of BambooEpoxy Composites: Effect of Silane Treatment of Mercerized Bamboo. J Appl Polym Sci. 2010;115(3):1846-52.

[3] Rassiah K, Ahmad MM, Ali A. Mechanical properties of laminated bamboo strips from Gigantochloa Scortechinii/polyester composites. Mater Des. 2014;57:551-9.

[4] Hung KC, Chen YL, Wu JH. Natural weathering properties of acetylated bamboo plastic composites. Polym Degrad Stabil. 2012;97(9):1680-5.

[5] Kim HJ, Seo DW, Lim JK, Fujii T. Tensile Properties and Water Absorption Behavior of Bamboo Fiber Reinforced Composites. Key Eng Mater. 2006;306:417-22.

[6] Naveen PN, Prasad RV. Evaluation of Mechanical Properties of Coconut Coir/Bamboo Fiber Reinforced Polymer Matrix Composites [IJMMSE]. International Journal of Metallurgical \& Materials Science and Engineering. 2013;3(4):15-22.

[7] Mounika M, Ramaniah K, Prasad AV, Rao KM, Reddy KH. Thermal Conductivity Characterization of Bamboo Fiber Reinforced Polyester Composite. J Mater Environ Sci. 2012;3(6):1109-16.

[8] Biswas S. Mechanical properties of bamboo-epoxy composites a structural application. Adv Mat Res. 2012;1(3):221-31.

[9] Nurul Fazita MR, Jayaraman K, Bhattacharyya D, Mohamad Haafiz MK, Saurabh CK, Hussin MH, et al. Green Composites Made of Bamboo Fabric and Poly (Lactic) Acid for Packaging ApplicationsA Review. Materials (Basel). 2016 Jun;9(6):435.

[10] Jena H, Pradhan AK, Pandit MK. Studies on water absorption behaviour of bamboo-epoxy composite filled with cenosphere. J Reinf Plast Compos. 2014;33(11):1059-68.

[11] Gupta A. Synthesis, chemical resistance, and water absorption of bamboo fiber reinforced epoxy composites. Polym Compos. 2014;37(1):141-5.

[12] Du L, Li Y, Lee S, Wu Q. Water Absorption Properties of HeatTreated Bamboo Fiber and High Density Polyethylene Composites. BioResources. 2014;9(1):1189-200.

[13] Papanicolaou GC, Kosmidou TV, Vatalis AS, Delides G. Water Absorption Mechanism and Some Anomalous Effects on the Mechanical and Viscoelastic Behavior of an Epoxy System. J Appl Polym Sci. 2005;99(4):1328-9.

[14] Cahyo DN, Pratiwi YR, Widiastuti I, Harjanto B, editors. Mechanical performances of bamboo composite with different fibre heat treatments. International Conference on Mathematics, Engineering And Industrial Applications 2018 (ICoMEIA 2018); 2018; Kuala Lumpur, Malaysia: AIP Publishing. https://doi.org/ $10.1063 / 1.5054200$.
[15] HACIOĞLU Y, YAMAK H, KAVAK N. The Opinions of Prospective Science Teachers Regarding STEM Education: The Engineering Design Based Science Education. GEFAD/GUJGEF. 2017;37(2):649 $-84$.

[16] Joseph S, Sreekala MS, Koshy P, Thomas S. Mechanical properties and water sorption behavior of phenol-formaldehyde hybrid composites reinforced with banana fiber and glass fiber. J Appl Polym Sci. 2008;109(3):1439-46.

[17] Adhikary KB, Pang S, Staiger MP. Long-term moisture absorption and thickness swelling behaviour of recycled thermoplastics reinforced with Pinus radiata sawdus. Chem Eng J. 2008;142(2):190-8.

[18] Najafi SK, Kiaefar A, Hamidina E, Tajvidi M. Water Absorption Behavior of Composites from Sawdust and Recycled Plastics. J Reinf Plast Compos. 2007;26(3):341-9.

[19] Mael A, Pierre-Yves LG, Maelenn LG, Christian B. Christophe Bo, Peter D. Modelling the non Fickian water absorption in polyamide 6. Polym Degrad Stabil. 2016;133:404-12.

[20] Eslami S, Taheri-Behrooz F, Taheri F. Effects of Aging Temperature on Moisture Absorption of Perforated GFRP. Adv Mater Sci Eng. 2012;2012:1-7.

[21] Li H, Xian Y, Deng J, Cheng H, Chen F, Wang G. Evaluation of water absorption and its influence on the physical-mechanical properties of bamboo-bundle laminated veneer lumber. BioResources. 2016;11(1):1359-68.

[22] Silva CJ, Barbosa de Lima AG, da Silva EG, de Andrade TH, da Costa Melo RQ. Lima Bd, Silva EGd, Andrade THFd, Melo RQdC. Water Absorption in Caroá-Fiber Reinforced Polymer Composite at Different Temperatures: A Theoretical Investigation. Diffusion Foundations. 2017;10:16-27.

[23] Jacob M, Varughese KT, Thomas S. A Study on the Moisture Sorption Characteristics in Woven Sisal Fabric Reinforced Natural Rubber Biocomposites. J Appl Polym Sci. 2006;102(1):416-23.

[24] Widiastuti I, Sbarski I, Masood S. Sorption characteristic of organic liquid and its effect on the mechanical performance of a PLA-based plastic. J Appl Polym Sci. 2016;133(20):1-9.

[25] Alomayri T, Assaedi H, Shaikh FU, Low M. Effect of water absorption on the mechanical properties of cotton fabric-reinforced geopolymer composite. Journal of Asian Ceramic Societies. 2014;2(3):223-30.

[26] Dhakal HN, Zhang ZY, Richardson MOW. Effect of water absorption on the mechanical properties of hemp fibre reinforced unsaturated polyester composites. Composites Science and Technology. 2007;67(7-8):1674-83. https://doi.org/10.1016/j.comps citech.2006.06.019.

[27] Widiastuti I, Sbarski I, Masood SH. Creep Behavior of PLA-Based Biodegradable Plastic Exposed to a Hydrocarbon Liquid. J Appl Polym Sci. 2012;127(4):2654-60.

[28] Yu YJ, Hearon K, Wilson TS, Maitland DJ. The effect of moisture absorption on the physical properties of polyurethane shape memory polymer foams. Smart Mater Struct. 2011 Aug;20(8):085010. 